\title{
Improvement of Xylanase Production by a Parasexual Cross between Aspergillus niger strains
}

\author{
Octavio Loera $^{1 *}$ and Jesús Córdova ${ }^{2}$ \\ ${ }^{I}$ Departamento de Biotecnología; Universidad Autónoma Metropolitana-Iztapalapa; Apdo. Postal 55-535; C. P. \\ 09340; México - D. F. - Mexico. ${ }^{2}$ Departamento de Ingeniería Química -- CUCEI; Universidad de Guadalajara; \\ C. P. 44480; Guadalajara - Jal. Mexico
}

\begin{abstract}
A diploid strain (D4) isolated via parasexual recombination between two Aspergillus niger xylanase overproducing mutants was characterised in terms of enzyme production and catabolite repression by glucose. This strain increased xylanase production $(607 \mathrm{nkat} / \mathrm{ml})$, which was nearly $100 \%$ higher than titers achieved by the wild type strain (305 nkat/ml) and 28\% higher than the best mutant used to induce parasexual cycle. Diploid D4 was also less sensitive to carbon catabolite repression by glucose, since xylanolytic activity was detected under conditions normally repressing production by the wild type strain. No decrease in maximal xylanase levels was observed in the presence of glucose for diploid D4.
\end{abstract}

Key words: Carbon repression, xylanase production, mutants, parasexual cross

\section{INTRODUCTION}

Xylanases comprise a group of enzymes able to catalyse the breakdown of xylan-containing substrates. These enzymes have been widely used in process such as paper industry (Gerber et al., 1997) and food industry (Coughlan and Hazlewood, 1993). Filamentous fungi are commonly used to produce xylanases and some improvements have been achieved in enzyme yields either by modifying culture conditions (Haltrich et al., 1996) or by isolating mutant strains (Singh et al., 1995).

Parasexual cycle has been described since it was first discovered in Aspergillus nidulans. It was also observed as a naturally occurring phenomenon in other species within the genera Aspergillus (Pontecorvo, 1956). In order to increase the production of different metabolites by
Aspergillus strains, parasexual crosses between selected strains have been used to enhance the production levels of metabolites such recombinant proteins (Bodie et al., 1994) and citric acid (Sarangbin et al., 1994). Antier et al. (1993) used the toxic glucose analogue 2-deoxy-D-glucose (2DG) to isolate improved Aspergillus niger strains resistant to this compound. Some of these mutants were able to overproduce pectinases in different media when compared to the wild type strain. These mutants were also less sensitive to carbon catabolic repression by glucose than the wild type strain A. niger C28B25. This observation was in agreement with some reports describing the isolation of 2DG-resistant strains which were also less sensitive to carbon catabolite repression (Kirimura et al., 1992; Gosh et al., 1991).

In this report, we describe the enhancement of xylanase production in comparison to the wild type

\footnotetext{
* Author for correspondence
} 
strain A. niger C28B25 achieved by a diploid strain, obtained by means of a parasexual cross between two of the mutants isolated by Antier et al. (1993).

\section{MATERIALS AND METHODS}

Microorganisms. Aspergillus niger haploid strains used were C28B25 (wild type) and mutant strains Aw99iii2 and Aw96-4, previously reported as pectinase overproducing strains in submerged fermentation (Antier et al., 1993). A diploid (D4) previously retrieved from a parasexual cross between arginine auxotrophs from strains Aw99iii2 and Aw96-4 (strains Aw99ARG and Aw96-4ARG) was also studied (Loera et al., 1999). All strains belonged to the Universidad Autónoma Metropolitana-Iztapalapa, Mexico, D.F., Mexico (UAM) fungal collection.

Culture Conditions. Minimal medium (MM) was prepared as described previously (Antier et al., 1993) with the following composition ( $\mathrm{g} / \mathrm{l})$ :

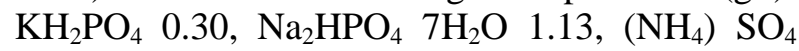
$0.75, \mathrm{MgSO}_{4} 7 \mathrm{H}_{2} \mathrm{O} 0.30$, urea 0.25 , and $\mathrm{CaCl}_{2}$ 0.30. Trace elements $\left(\mathrm{ZnSO}_{4}, \mathrm{FeSO}_{4}, \mathrm{MnSO}_{4}\right.$ and $\mathrm{CuSO}_{4}$ ) were also added to a final concentration of $1 \mathrm{mg} / \mathrm{l}$ according to Bos et al. (1992). These MM cultures were added with $10 \mathrm{~g} / \mathrm{l}$ of xylan from birchwood (Roth) as a sole carbon source plus 5 $\mathrm{g} / \mathrm{l}$ of glucose when indicated. Erlenmeyer flasks $(250 \mathrm{ml})$ containing $50 \mathrm{ml}$ of this medium were inoculated with $10^{4}$ spores $/ \mathrm{ml}$ of the appropriate strain. All cultures were incubated at $30^{\circ} \mathrm{C}$ on an orbital shaker at $180 \mathrm{rpm}$. Samples were taken and filtered through Whatman No. 4 filter paper and filtrate was assayed for enzyme activity.

Enzymatic Assays. Xylanase activity was assayed by detection of reducing sugars using the dinitrosalicylic acid (DNS) method (Miller, 1959). The substrate was a $1 \%$ xylan from birchwood in $50 \mathrm{mM}$ citric-Na citrate buffer $\mathrm{pH} 5.3$ and a series of dilutions from a stock solution of xylose in the same buffer were used as standards. The reaction mixture total volume was $2 \mathrm{ml}$, consisting of 1.8 $\mathrm{ml}$ of substrate and $0.2 \mathrm{ml}$ of appropriate enzyme solution. The incubation time was $5 \mathrm{~min}$ at $50^{\circ} \mathrm{C}$, then $3 \mathrm{ml}$ of DNS reagent was added to stop the reaction. The colour was developed by boiling the samples for $5 \mathrm{~min}$ and then placing them immediately on ice for $5 \mathrm{~min}$ prior to taking an aliquot of $1 \mathrm{ml}$ into a disposable plastic cuvette.
The absorbance was measured at $540 \mathrm{~nm}$ against a blank prepared in the same way but with $0.2 \mathrm{ml}$ of $50 \mathrm{mM}$ citrate-Na citrate buffer $\mathrm{pH} 5.3$ as a sample. Absorbance at $540 \mathrm{~nm}$ due to the xylanase activity could be related to the amount of reducing sugars (xylose) present by comparison with a standard curve. Enzyme activity in a given assay took into account the volume of the assay and expressed as $\mathrm{nkat} / \mathrm{ml}$, where one nanokatal represented the amount of enzyme that released $1 \mathrm{nmol}$ of reducing sugar (expressed as xylose equivalents) per second under these assay conditions. Results shown represent the average of three determinations and observed variations were under $10 \%$ of mean values.

\section{RESULTS AND DISCUSSION}

Xylanase production by each strain was determined in media containing xylan as carbon source in the presence or absence of glucose as a repressing sugar. Glucose has been previously shown to repress the expression of pectinases in the wild type strain using similar MM containing pectin at a final concentration of $10 \mathrm{~g} / \mathrm{l}$ (Antier et al., 1993). Figure 1 presents the xylanolytic activity by the wild type strain C28B25 and the diploid construct D4 in a MM with xylan as a sole carbon source. Diploid D4 was able to produce nearly twice as much xylanolytic activity (607 $\mathrm{nkat} / \mathrm{ml}$ ) at the time of its maximal production (96 h) in comparison with strain C28B25 (305 nkat $/ \mathrm{ml})$. Once xylanolytic activity was detected, there was a constant increase in the production by diploid D4 whereas strain C28B25 seemed to reach a production peak at $88 \mathrm{~h}$ (Fig. 1). This overproduction pattern by strain D4 has been observed previously for pectinases (Loera et al., 1999; Loera and Viniegra-González, 1998). Similarly, a constant increase in xylanase production was also confirmed for mutants Aw99iii2 and Aw96-4 in a time course determination for a period of $144 \mathrm{~h}$, but these two mutants showed always lower production levels than those achieved for diploid strain D4 (data not shown). The presence of glucose in the culture medium resulted in strong repression of xylanase for the wild type strain. There was not any notable enzymatic activity detected during the first $72 \mathrm{~h}$ (Fig. 2), whereas in the medium with xylan as the only carbon source, strain C28B25 produced 190 nkat/ml at 72 h (Fig. 1). 


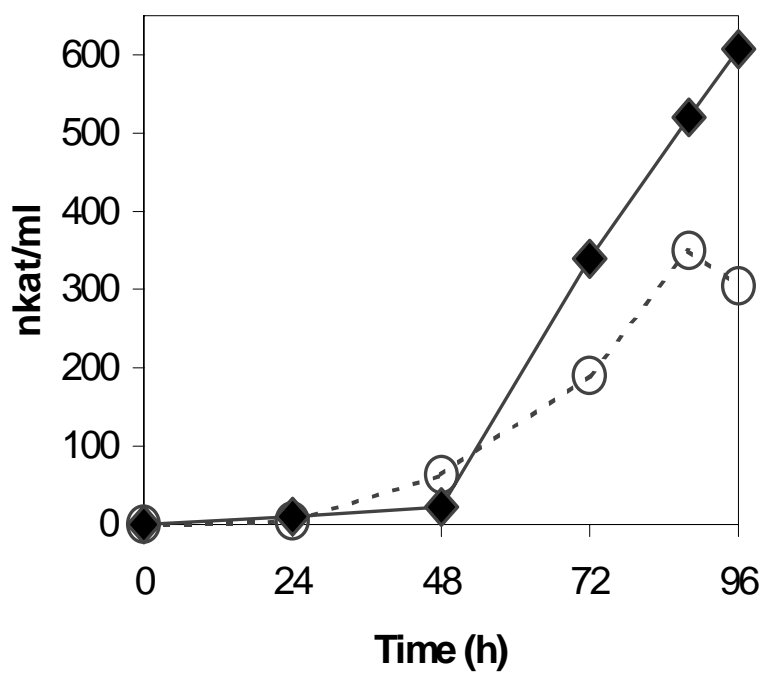

Figure 1 - Comparison of xylanase activity in a Submerged Fermentation with xylan as the sole carbon source by A. niger haploid wild type strain C28B25 (O, broken line) and diploid strain D4 ( $\bullet$, solid line).

Interestingly, a different effect was observed for the diploid strain D4 since this strain was able to excrete xylanases into the medium continuously along the culture. Even after $24 \mathrm{~h}$, xylanolytic activity was $39 \mathrm{nkat} / \mathrm{ml}$ as shown in Fig. 2, whereas in a medium with no glucose, xylanase activity was only $10 \mathrm{nkat} / \mathrm{ml}$ for diploid D4 at $24 \mathrm{~h}$ (Fig. 1). This diploid was constructed from two 2DG-resistant mutant strains (Loera et al., 1999), showing also a less sensitive phenotype in terms of carbon catabolite repression (Antier et al., 1993).This was also confirmed for the xylanase enzymatic family in these strains as shown in Fig. 3 where activity at $96 \mathrm{~h}$ has been presented. In the case of mutant Aw99-iii2, xylanolytic activities were $421 \mathrm{nkat} / \mathrm{ml}$ and $483 \mathrm{nkat} / \mathrm{ml}$ in cultures without or with glucose, respectively. Mutant strain Aw96-4 reached $351 \mathrm{nkat} / \mathrm{ml}$ and 425 nkat $/ \mathrm{ml}$ in the same medium, respectively.

Some interesting features about diploid D4 can be remarked. Firstly, it retains the ability to overproduce enzymes, even at higher titres to those achieved for the original mutants. On the other hand, it also retains the derepression phenotype as compared to the wild type strain in the presence of glucose. Nevertheless, a previous report revealed that this diploid reverted to the wild phenotype of 2DG sensitivity, indicating that 2DG-resistance was not a necessary phenotype for the overproduction of enzymes (Loera et al., 1999).

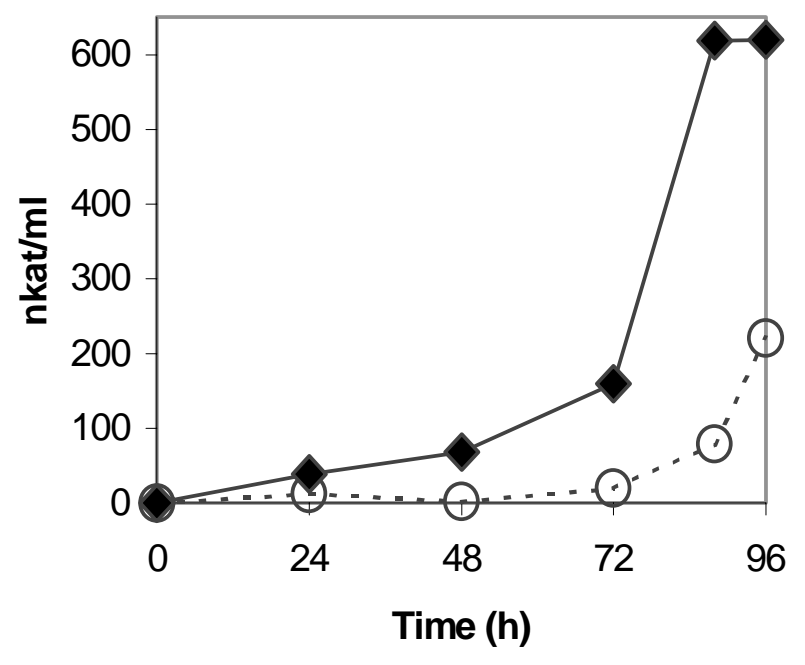

Figure 2 - Comparison of xylanase activity in a Submerged Fermentation with xylan and glucose as carbon sources by $A$. niger haploid wild type strain C28B25 (O, broken line) and diploid strain D4 $(\diamond$, solid line).

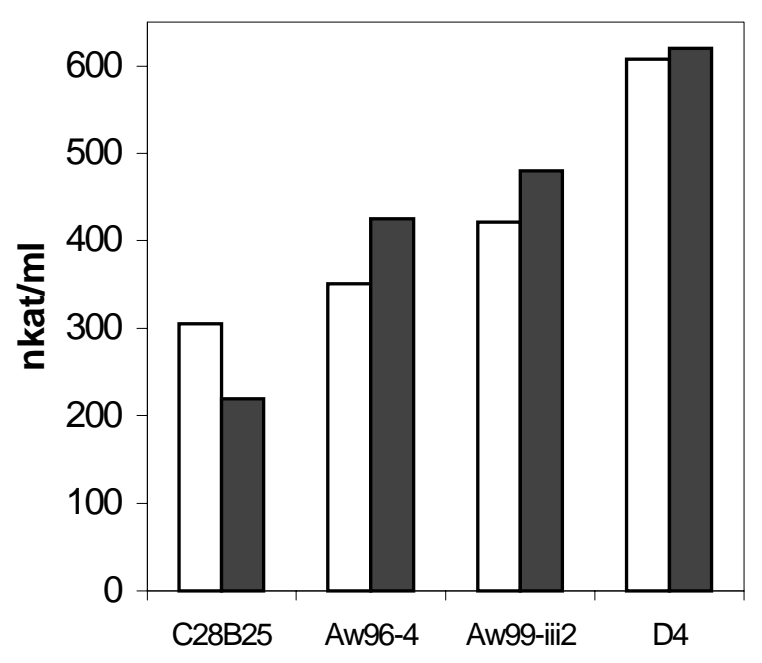

Figure 3 - Comparison of xylanase activity by A. niger strains in Submerged Fermentation at $96 \mathrm{~h}$ of cultivation with xylan as the sole carbon source (clear boxes) and with xylan plus glucose as carbon sources (solid boxes). Results shown are means of two determinations and observed variations were under $15 \%$ of mean values.

One possibility to explain xylanase overproduction by strain D4 could be the fact that diploidy enabled to double those genes involved in enzyme synthesis, including positive transcription factors 
in a background where negative regulators were possibly eliminated or modified. The latter could be considered since random mutagenesis was applied in order to isolate overproducing mutants such as Aw99-iii2 and Aw96-4. Moreover, consideration of altered regulatory genes, rather than any enzymatic structural gene in particular, resulted form the fact that overproducing patterns were observed in those mutants for different enzymes such pectinases (Loera et al., 1999), invertase (Montiel-González et al., 2002) and glucoamylases (Loera, unpublished data).

Xylanase levels achieved by strain D4 were similar to those titers obtained by filamentous fungi like Fusarium monolifirme and Trichoderma reesei (Vazquez et al., 1997). However higher titers could be expected with different culture conditions once an improved strain has been obtained. In particular, manipulation of agitation and dissolved oxygen has proven to modify xylanase titers by Thermomyces lanuginosus in a range of one order of magnitude (Singh et al., 2000). This is relevant for xylanases of Aspergillus niger since application of the crude xylanolytic preparation of this fungus have found applications in paper industry (Maximo et al., 1998).

Our results showed that parasexual recombination could be considered to further improve xylanase production by $A$. niger strains.

\section{ACKNOWLEDGMENT}

This work was partially financed by the Consejo Nacional de Ciencia y Tecnología (Conacyt, México) and the Universidad Autónoma Metropolitana.

\section{RESUMO}

Um cepa diplóide (D4) isolada por combinação parasexual entre dois Aspergillus niger, mutantes superprodutores de xylanase foi caracterizado através da produção de $(607 \mathrm{nkat} / \mathrm{ml})$ e repressão catabólica por glicose. Essa cepa aumenta a produção de xylanase em mais de $100 \%$ em comparação com uma cepa selvagem (305 $\mathrm{nkat} / \mathrm{ml}$ ) e $28 \%$ superior do que o melhor mutante usado para induzir o ciclo parasexual. A cepa diplóide D4 foi também menos sensível a repressão catabólica pela glicose, sendo que a atividade xylanolitica foi detectada sob condições normalmente de produção repressiva pela cepa selvagem. Não foi observado um decréscimo na produção máxima de xylanase em presença de glicose para o diplóide D4.

\section{REFERENCES}

Antier, P.; Minjares, A.; Roussos, S.; Raimbault, M.; and Viniegra-González, G. (1993), Pectinase hyperproducing mutants of Aspergillus niger C28B25 for solid state fermentation on coffee pulp. Enzyme Microb. Technol., 15, 254-260.

Bodie, E. A.; Armstrong, G. L. and Dunn-Coleman, N. S. (1994), Strain improvement of chymosinproducing strain of Aspergillus niger var. awamori using parasexual recombination. Enzyme Microb. Technol., 16, 376-382.

Coughlan, M. P. and Hazlewood, G. P. (1993), ß-1,4D-xylan-degrading enzyme systems: biochemistry, molecular biology and applications. Biotech. Appl. Biochem., 17, 259-289.

Gerber, P. J.; Heitmann, J. A. and Joyce, T. W. (1997), Purification and characterization of xylanases from Trichoderma. Bioresource Technology, 61,127-140.

Gosh, A.; Chatterjee, B. and Das, A. (1991) Production of glucoamylase by 2-deoxy-D-glucose resistant mutant of Aspergillus terreus. Biotech. Lett., 13, 515-520.

Haltrich, D.; Nidetzky, B.; Kulbe, K. D.; Steiner, W. and Zupancic, S. (1996), Production of fungal xylanases. Bioresource Technology, 58, 137-161.

Kirimura, K.; Saragbin, S.; Rugsaseel, S. and Usami, S. (1992), Citric acid production by 2-deoxyglucose resistant mutant strain of Aspergillus niger. Appl. Microbiol. Biotechnol, 36, 573-577.

Loera, O. and Viniegra-González, G. (1998), Identification of growth phenotypes in Aspergillus niger pectinase overproducing mutants using image analysis procedures. Biotechnol. Tech., 12, 801-804.

Loera, O.; Aguirre, J. and Viniegra-González, G. (1999), Pectinase production by a diploid construct from two Aspergillus niger overproducing mutants. Enzyme Microb. Technol., 25, 103-105.

Maximo, C.; Costa-Ferreira, M. and Duarte, J. (1998), Some properties of eucalyptus kraft pulp treated with xylanase from Aspergillus niger. World J. Microbiol. Biotechnol., 14, 365-367.

Miller, G. L. (1959), Use of dinitrosalicylic acid reagent for determination of reducing sugars Anal Chem., 31, 426-428.

Montiel-González, A. M.; Fernández, F. J.; ViniegraGonzález, G. and Loera, O. (2002), Invertase production on solid state fermentation by Aspergillus niger strains improved by parasexual recombination. Appl. Biochem. Biotechnol. [In Press]. 
Pontecorvo, G. (1956), The parasexual cycle. Ann. Rev. Microbiol., 10, 393-400.

Sarangbin, S.; Morikawa, S.; Kirimura, K. and Usami, S. (1994), Formation of autodiploid strains in Aspergillus niger and their application to citric acid production from starch. J. Ferment. Bioeng., 77, 474-478.

Singh, A., Kuhad, R. C. and Kumar, M. (1995), Xylanase production by a hyperxylanolytic mutant of Fusarium oxysporum. Enzyme Microb.. Technol., 17, 551-553.

Singh, S.; du Preez, J. C.; Pillay, B. and Prior, B. A. (2000), The production of hemicellulases by Thermomyces lanuginosus strain SSBP: influence of agitation and dissolved oxygen tension. Appl. Microbiol. Biotechnol., 54, 698-704.

Vazquez, F.; Heluane, H.; Spencer, J. F. T.; Spencer, D. M. and De Figueroa, L. I. C. (1997), Fusion between protoplasts of Pichia stipitis and isolated filamentous fungi nuclei. Enzyme Microb. Technol., 21, 32-38. 